\title{
Identification and characterization of biomarkers and their functions for docetaxel-resistant prostate cancer cells
}

\author{
LEIHONG DENG ${ }^{1}$, XIAOPENG GU ${ }^{2}$, TAO ZENG $^{3}$, FANGHUA XU $^{4}$,

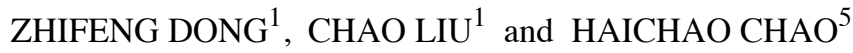 \\ ${ }^{1}$ Medical Department of The Graduate School, Nanchang University, Nanchang, Jiangxi 330006; \\ ${ }^{2}$ Department of Orthopedics, Zhoushan Guhechuan Hospital, Zhoushan, Zhejang 316000; \\ ${ }^{3}$ Department of Urology, ${ }^{4}$ Pathology Department, ${ }^{5}$ Laboratory of Clinical Medicine, \\ Jiangxi Provincial People's Hospital Affiliated to Nanchang University, Nanchang, Jiangxi 330006, P.R. China
}

Received November 3, 2018; Accepted June 13, 2019

DOI: $10.3892 /$ ol.2019.10623

\begin{abstract}
Docetaxel treatment is a standard chemotherapy strategy for castration-resistant prostate cancer (CRPC), and patients with CRPC eventually develop resistance to treatment. However, little is understood regarding the underlying mechanism of resistance. The present study aimed to identify the underlying crucial genes and regulatory networks associated with docetaxel resistance in prostate cancer using bioinformatics analyses. For this purpose, one expression profile dataset (GSE33455), which included two docetaxel-sensitive and two docetaxel-resistant cell lines, was downloaded from the Gene Expression Omnibus database, and analyses of differential gene expression and function enrichment were performed. A protein-protein interaction (PPI) network was constructed, and the associated hub genes were investigated using the Search Tool for the Retrieval of Interacting Genes/Proteins and Cytoscape software. A total of 756 differentially expression genes (DEGs) were identified, including 509 downregulated and 247 upregulated genes. Enrichment analysis revealed that the DEGs were associated with the interferon- $\gamma$-mediated signaling pathway, protein binding, bicellular tight junctions and cancer pathways. Two modules were screened from the PPI network, and the corresponding genes were identified to be largely enriched in the interferon- $\gamma$-mediated signaling pathway and the negative regulators of the $\mathrm{DExD} / \mathrm{H}-\mathrm{Box}$ helicase 58/interferon induced with helicase $\mathrm{C}$ domain 1 signaling pathway, and enriched in cell-cell adhesion and the Rap1 signaling pathway. Among the ten hub genes, epidermal growth factor receptor, spleen tyrosine kinase (SYK), intracellular adhesion molecule 1
\end{abstract}

Correspondence to: Dr Haichao Chao, Laboratory of Clinical Medicine, Jiangxi Provincial People's Hospital Affiliated to Nanchang University, 152 Ai-Guo Road, Nanchang, Jiangxi 330006, P.R. China E-mail: chaohaichaovip@sina.com

Key words: docetaxel-resistant, prostate cancer, differentially expressed genes, protein-protein interaction network, hub genes
(ICAM1), interleukin (IL)6, CXC motif chemokine ligand 8 (CXCL8), cyclin dependent kinase 1 and CD44 molecule (CD44) were significantly differentially expressed in prostate cancer tissues compared with healthy tissues based on The Cancer Genome Atlas data. The Gene Expression Profiling Interactive Analysis database revealed that ICAM1 was positively associated with IL6 and CXCL8, and epidermal growth factor receptor was positively associated with CD44 and SYK. Additionally, ten hub genes, which were identified to be associated with the drug resistance of docetaxel in prostatic carcinoma in the present study, were predominantly associated with tumor progression and metastasis. Reverse transcription-quantitative PCR analysis performed on docetaxel-sensitive and docetaxel-resistant prostate cancer cell lines demonstrated that certain hub genes, including CDK1, 2'-5'-oligoadenylate synthetase 3, CXCL8 and CDH1, were highly expressed in the docetaxel-resistant cell lines, which confirmed the bioinformatics results. In conclusion, the present study identified a number of important genes that are associated with the molecular mechanism of docetaxel resistance by integrated bioinformatical analysis, and these genes and regulatory networks may assist with identifying potential gene therapy targets for CRPC. Further functional analyses are required to validate the current findings.

\section{Introduction}

Prostate cancer (PCa), which exhibits complicated pathogenesis and treatment difficulties, is the most common malignancy of the male reproductive system worldwide, accounting for 29,430 deaths in the USA in 2018 (1). PCa is a global public issue that threatens human health and life, with increasing morbidity and mortality rates each year (2). Metastatic PCa is commonly treated with androgen deprivation therapy; however, resistance can still develop quickly, which leads to castration-resistant PCa (CRPC) (3). Docetaxel is widely used as the standard first-line chemotherapy treatment for patients with CRPC (3). The majority of patients with CRPC who receive docetaxel chemotherapy develop resistance to this treatment. Additionally, with increasing treatment times and doses, complications may occur (4). Therefore, further 
investigation regarding the mechanism of docetaxel-resistant PCa may improve the prognosis of patients with PCa.

Although the mechanism underlying $\mathrm{PCa}$ drug resistance has been extensively studied, its cause and pathogenesis remain poorly understood. The current consensus is that the mechanism of docetaxel-resistant $\mathrm{PCa}$ is associated with multiple factors, including androgen receptor splice variant expression (5), changes in the expression of $\beta$-tubulin (6), multidrug resistance induced by abnormal expression of the ATP binding cassette (ABC) transporter family and abnormal expression of signaling pathway factors (7), including the PI3K/AKT/mTOR (8), Wnt (9) and NF- $\kappa$ B/interleukin (IL)6 pathways (10). Additionally, abnormal expression levels of EMT and stem-like cell markers have been detected in PCa cells resistant to docetaxel, which lead to a downregulation of cadherin 1 (CDH1) and an upregulation of vimentin, zinc finger E-box binding homeobox 1 and the stem-like cell marker CD44 molecule (CD44) (11). Taken together, these studies suggest that docetaxel resistance in PCa occurs due to alterations in numerous factors and/or genetic changes, rather than a single factor. Although these basic and clinical studies have investigated the resistance of docetaxel in $\mathrm{PCa}$ in the past few decades with the aim of revealing the potential underlying mechanisms, the effect of treatment remains unsatisfactory (5-11). Therefore, understanding the precise molecular mechanisms associated with the development of docetaxel resistance in $\mathrm{PCa}$ is essential for the improvement of effective diagnosis and treatment strategies. Microarray technologies, which have widely been used to investigate large scale gene expression simultaneously, presents an effective method to investigate the expression of tens of thousands of genes and identify the mechanisms of numerous diseases, particularly cancers. The integration and analysis of microarray data provide valuable information for the study of docetaxel resistance (12).

In this present study, the GSE33455 microarray dataset (13), which includes two docetaxel-sensitive and two docetaxel-resistant cell lines, was downloaded from the Gene Expression Omnibus (GEO) database, and differentially expressed genes (DEGs) between the two types of PCa cell lines were identified. Functional enrichment analyses and functional annotation were performed and a protein-protein interaction (PPI) network was constructed and analyzed to screen potential therapeutic targets for docetaxel resistance using the Search Tool for the Retrieval of Interacting Genes/Proteins (STRING) database and Cytoscape software. Reverse transcription-quantitative PCR analysis was performed to investigate the expression of the hub genes in docetaxel-sensitive and docetaxel-resistant PCa cell lines and to further validate their potential roles in docetaxel resistance in $\mathrm{PCa}$.

\section{Materials and methods}

Data collection. The microarray expression profile dataset GSE33455 (13) was downloaded from the GEO database (http://www.ncbi.nlm.nih.gov/geo), which is based on the GPL570 [HG-U133_Plus_2] Affymetrix Human Genome U133 Plus 2.0 Array. The dataset contained 12 sets of data from four cell lines, including PCa cell lines DU-145 (docetaxel-sensitive), PC-3 (docetaxel-sensitive), DU-145R (docetaxel-resistant) and PC-3R (docetaxel-resistant).

Analysis of DEGs. The original expression data underwent background correction and quartile data normalization and was converted into gene expression measures using the robust multiarray average (14) in the R Affy package (release 3.9; http://www. bioconductor.org/packages/release/bioc/html/affy.html). The DEGs between docetaxel-sensitive and docetaxel-resistant samples were analyzed using the limma package (15) in Bioconductor (http://www.bioconductor.org), and a DEG was considered to be significant according to the following criteria: $\mid \log [$ fold-change (FC)]l>2 and false discovery rate (FDR) $<0.05$. Subsequently, a heatmap was constructed and the DEGs were identified using the pheatmap package of R software (16).

Gene ontology (GO) and Kyoto Encyclopedia of Genes and Genomes (KEGG) pathway analyses. GO is a tool used to annotate genes, collect and analyze information according to cellular component (CC), biological process (BP) and molecular function $(\mathrm{MF})$ terms following the criteria $\mathrm{P}<0.05$ (17). KEGG is an online database and analysis tool for integrating and interpreting large molecular datasets (18). Database for Annotation, Visualization and Integrated Discovery (DAVID; https://david.ncifcrf.gov) is a website composed of a comprehensive biological database and analysis tools that assist with the understanding of the biological meaning of gene lists (19). In the present study, DAVID and Metascape (https://metascape.org) were used for GO and KEGG pathway enrichment analyses of the DEGs. FDR $<0.05$ was considered to indicate a statistically significant result.

Analysis of the PPI network. The STRING database is an online biological database that collects comprehensive information on proteins to evaluate the PPI information (20). In the current study, significant gene pairs of the PPI network were visually represented using Cytoscape; a combined score $>0.4$ was considered as significant and the strength of an interaction was modelled by the number of lines (21). Cytoscape is a bioinformatics software used to perform computational analysis of cellular networks and merge experimental omics datasets together (22). The hub genes were selected using the CytoHubba network analyzer plug-in (23). In addition, analysis of the most important module was performed using the MCODE plug-in for Cytoscape. Subsequently, Metascape (http://metascape.org/gp/index.html) software was used for functional enrichment analysis of the module genes.

Analysis of hub gene expression levels. RNA-sequencing data of $497 \mathrm{PCa}$ and 52 adjacent normal tissue samples were downloaded from The Cancer Genome Atlas (TCGA) database (https://cancergenome.nih.gov/) to examine the expression levels of the hub genes. Gene Expression Profiling Interactive Analysis (GEPIA; http:/gepia2.cancer-pku. cn/\#index, accessed on May 4th, 2019) is a newly developed interactive web server for analyzing the RNA-sequencing expression data of 9,736 tumor samples and 8,587 normal samples from TCGA and GTEx projects using a standard processing pipeline. GEPIA provides customizable functions, including tumor/normal differential expression analysis, 
profiling according to cancer types or pathological stages, patient survival analysis, similar gene detection and correlation analysis (24). The present study used GEPIA to analyze the associations between the identified hub genes. GEPIA uses the non-log scale for calculation and uses the log-scale axis for visualization. This function of GEPIA performs pairwise gene expression correlation analysis for given sets of TCGA and/or GTEx expression data using a variety of methods, including Pearson, Spearman and Kendall analyses.

Cell lines. The human PCa cell lines DU-145 and PC-3, purchased from the Type Culture Collection of the Chinese Academy of Sciences were maintained in MEM (Gibco; Thermo Fisher Scientific, Inc.) or F12K (Gibco; Thermo Fisher Scientific, Inc.), respectively. The media were supplemented with $10 \%$ fetal calf serum (Gibco; Thermo Fisher Scientific, Inc.). The DU-145R and PC-3R cell lines were developed by docetaxel dose escalation, as previously described (25). Cells were cultured at $37^{\circ} \mathrm{C}$ in a $5 \% \mathrm{CO}_{2}$ incubator.

RNA extraction and reverse transcription-quantitative PCR. Total RNA was extracted from cells using TRIzol ${ }^{\circledast}$ reagent (Invitrogen; Thermo Fisher Scientific, Inc.) and reverse transcribed into cDNA templates using PrimeScript ${ }^{\circledR}$ RT Reagent kit (Takara Biotechnology Co., Ltd.) according to the manufacturer's instructions. The mRNA expression levels were evaluated using SYBR ${ }^{\circledR}$ Green Master Mix (Takara Biotechnology Co., Ltd.) and a CFX96 PCR machine (Bio-Rad Laboratories, Inc.). The thermocycling conditions were as follows: $10 \mathrm{~min}$ at $95^{\circ} \mathrm{C}$, 40 cycles of $15 \mathrm{sec}$ at $95^{\circ} \mathrm{C}$ and $60 \mathrm{sec}$ at $60^{\circ} \mathrm{C}$, followed by $1 \mathrm{~h}$ at $4^{\circ} \mathrm{C}$. B-actin was used as an internal reference for normalization. Compared with the control, the fold change in mRNA levels was calculated using the $2^{-\Delta \Delta C q}$ method (26). The specific PCR primers for the hub genes and $\beta$-actin as the housekeeping gene were designed with Primer Express version 2.0 (Applied Biosystems, Carlsbad, CA, USA) and are presented in the Table SI.

Statistical analysis. The PCR data were presented as the mean \pm standard deviation and analyzed using SPSS 19.0 statistical software (IBM Corp.). Differences between the two types of PCa cell lines were analyzed using Student's t-test. $\mathrm{P}<0.05$ was considered to indicate a statistically significant difference.

\section{Results}

Identification of DEGs. The gene expression dataset GSE33455 was downloaded from the GEO database and included data for two docetaxel-sensitive PCa cell lines and two docetaxel-resistant PCa cell lines. Following differential expression analysis, 756 DEGs were identified between docetaxel-sensitive and docetaxel-resistant $\mathrm{PCa}$, including 247 upregulated and 509 downregulated genes. A heatmap was constructed using the top 100 DEGs based on their FC (Fig. 1).

GO and pathway enrichment analyses. The biological functions of all identified DEGs were evaluated by GO and pathway enrichment analyses, which were performed using DAVID and Metascape. In the enrichment analysis of BPs, the DEGs were significantly enriched in 'type I interferon signaling pathway', 'interferon-gamma-mediated signaling pathway', 'epidermis development', 'defense response to virus' and 'transforming growth factor beta receptor signaling pathway' (Fig. 2A). In the MF analysis, the DEGs were significantly enriched in 'protein binding', 'identical protein binding', 'cadherin binding involved in cell-cell adhesion' and 'actin binding' (Fig. 2B). In the $\mathrm{CC}$ analysis, the DEGs were predominantly enriched in 'bicellular tight junction', 'cytosol', 'extracellular exosome' and 'receptor complex' (Fig. 2C). The top five GO terms of the DEGs are presented in Tables SII and SIII.

KEGG pathway analysis indicated that the DEGs were significantly enriched in 'metabolic pathways', 'pathways in cancer', 'PI3K-Akt signaling pathway' and other significant signaling pathways with the highest gene numbers $(\mathrm{P}<0.05$; Table SIV; Fig. 3). The majority of these pathways are closely associated with the occurrence and progression of tumors.

PPI network analysis and module selection. The PPI network of the DEGs was constructed using the STRING online database and consisted of 324 nodes and 1,087 edges (Fig. 4A). The results were then transferred to Cytoscape software to analyze the interactions between the candidate DEGs in PCa. The Cytoscape cytoHubba Network Analyzer plug-in selected ten hub genes from the PPI network by identifying the top ten nodes ranked by degree. To investigate the significant modules in this PPI network, two significant modules were obtained by Cytotype MCODE, with enrichment scores of 11.053 and 5.3 , respectively, and all of the MCODE scores for the two significant modules were $>5$. The results of functional enrichment analysis indicated that module one consisted of 18 nodes and 105 edges (Fig. 4B), which were predominantly enriched in the 'defense response to virus', 'interferon-gamma-mediated signaling pathway' and 'negative regulators of DDX58/IFIH1 signaling' (Table I). Module two consisted of 19 nodes and 53 edges (Fig. 4C), which were predominantly associated with the 'regulation of peptidyl-tyrosine phosphorylation', 'DNA replication', 'cell-cell adhesion' and the 'Rap1 signaling pathway' (Table II).

The top ten DEGs with high degrees of connectivity were considered as the hub genes of resistant PCa, and a degree $>28$ was identified as the central node degree used to determine hub genes as the degree of the tenth gene was 29 . These hub genes, ranked by node degree, including intercellular adhesion molecule 1 (ICAM1), Spleen-associated tyrosine kinase SYK, Cyclin-dependent kinase 1 (CDK1),2'-5'-oligoadenylate synthetase-like (OASL), 2'-5'-oligoadenylate synthetase 3 (OAS3), CXC motif chemokine ligand 8 (CXCL8), CD44, CDH1, epidermal growth factor receptor (EGFR) and IL6, were identified as the key candidate genes, which may serve crucial roles in cancer drug resistance (Fig. 4D). The degrees and functions of the top ten hub genes in the PPI network are presented in Table III, and these genes/proteins may be associated with the docetaxel resistance of PCa.

Hub gene validation using TCGA database. To validate the hub genes, the expression levels of the hub genes were analyzed using data from TCGA database. The results indicated that the expression levels of ICAM1 and CDK1 were significantly higher in PCa tissues compared with normal 


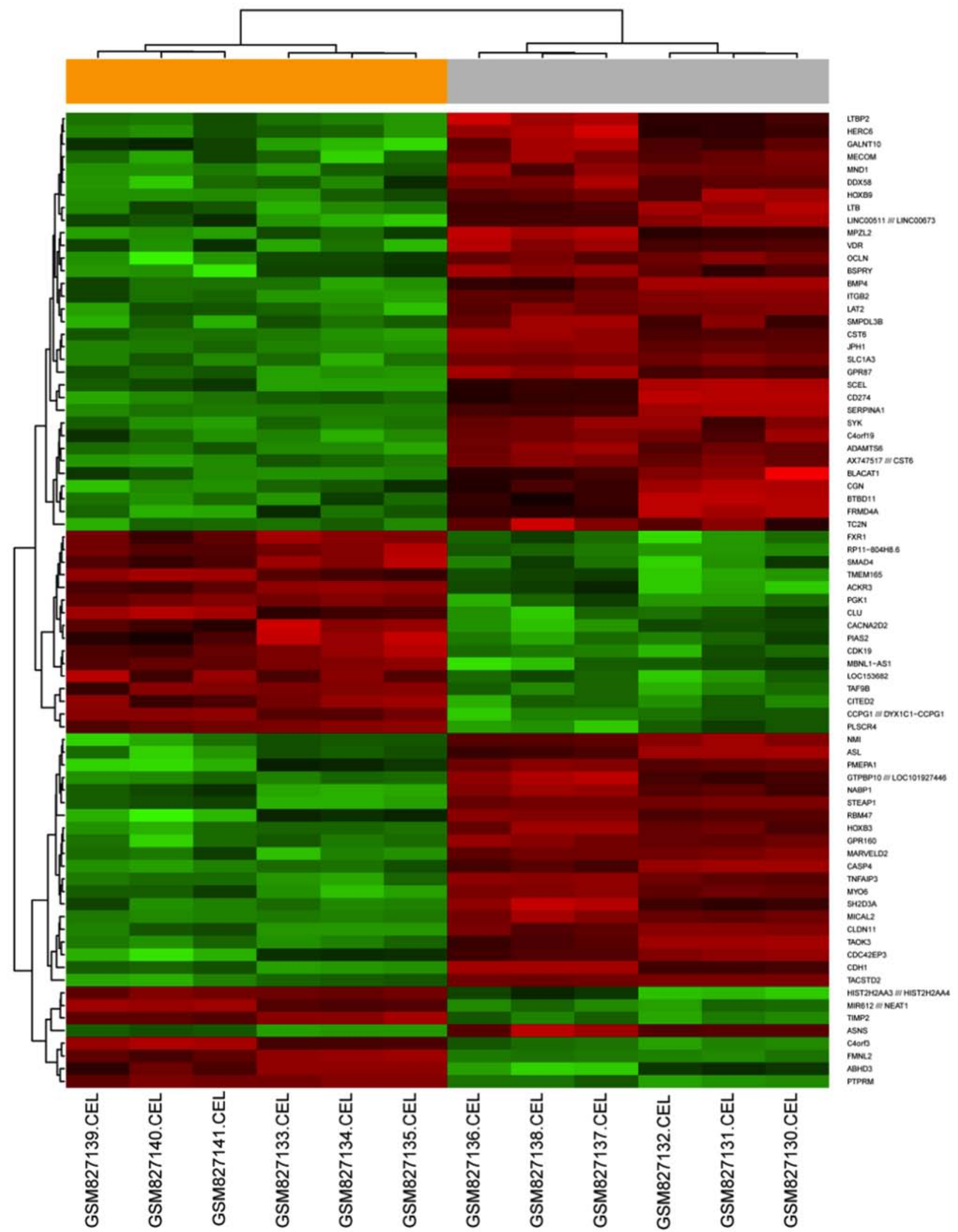

Figure 1. Heatmap of the top 100 differentially expressed genes. Red indicates a high expression level and green indicates a low expression level.

tissues (Fig. 5A and C), whereas the expression levels of SYK, CXCL8, CD44, EGFR and IL6 were lower in PCa tissues compared with normal tissues (Fig. 5B, F, G, I and J).
However, there was no significant difference in the expression levels of OASL, OAS3 and CDH1 between PCa tissues and normal tissues (Fig. 5D, E and $\mathrm{H}$ ). 
A Biological process

interferon-gamma-mediated signaling pathway type I interferon signaling pathway epidermis development defense response to virus cellular response to hydrogen peroxide transforming growth factor beta receptor signaling pathway cell-cell adhesion bicellular tight junction assembly hematopoietic progenitor cell differentiation branching involved in salivary gland morphogenesis

0

\section{B Molecular function}

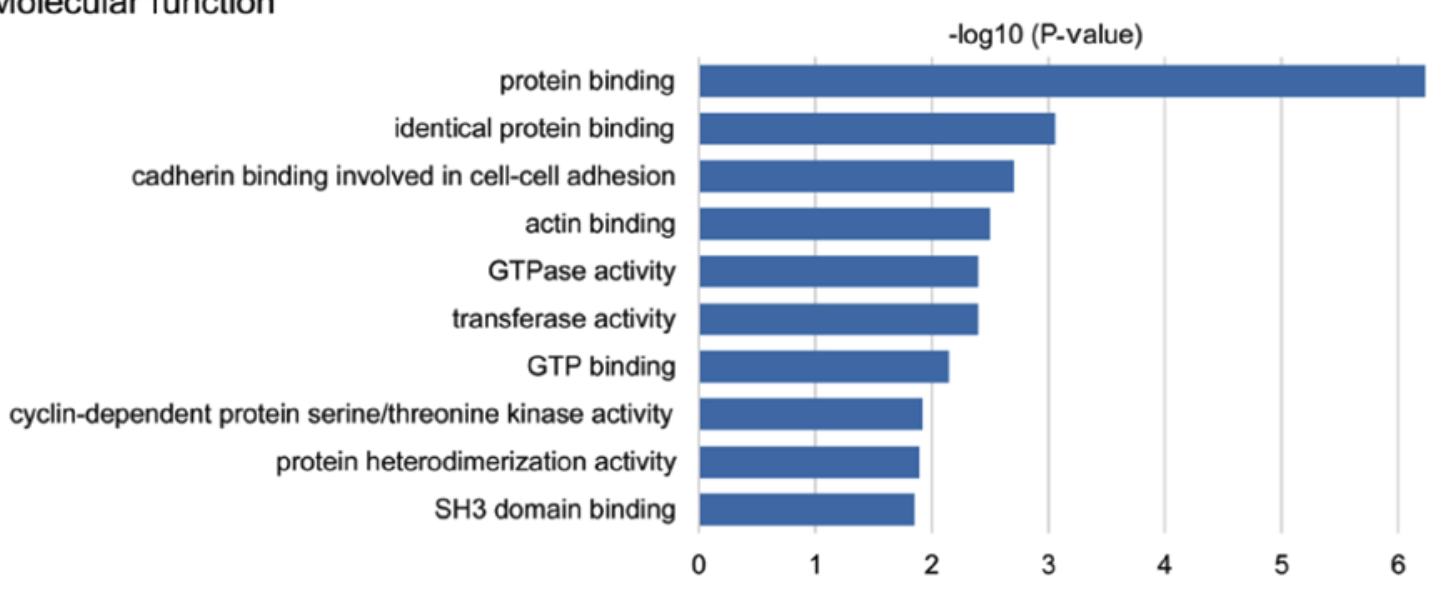

\section{Cellular components}

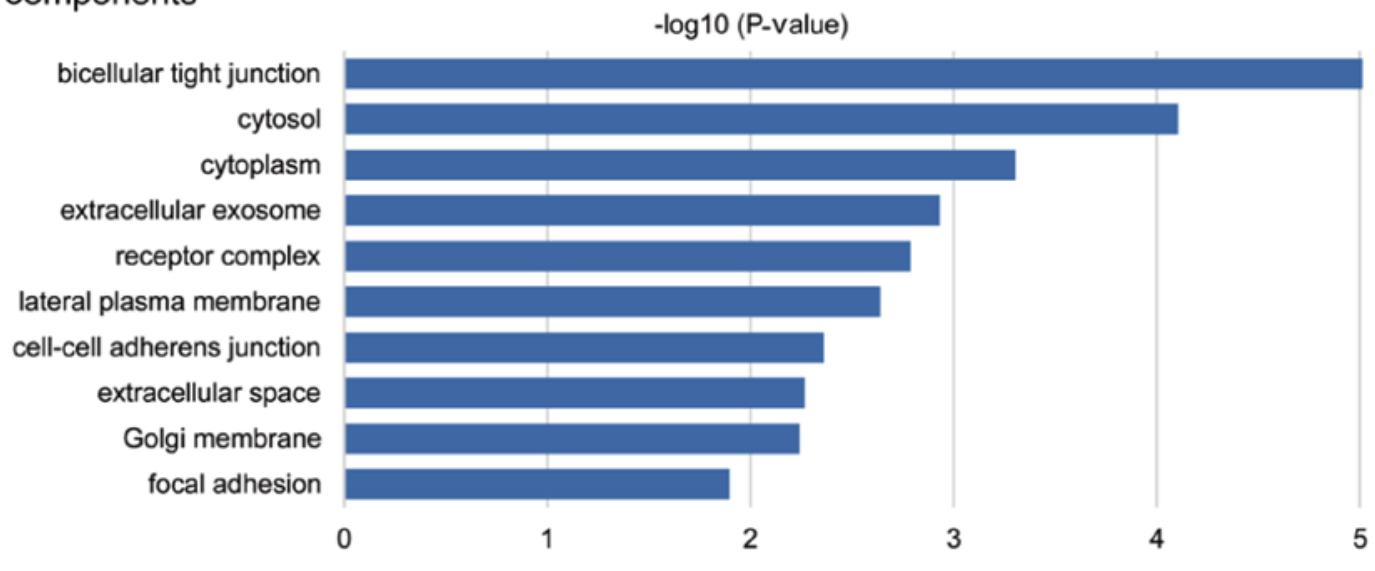

Figure 2. Gene Ontology enrichment analysis of the differentially expressed genes. (A-C) The numbers of enriched genes according to the (A) biological process, (B) molecular function and (C) cellular component categories.

Correlations among the expression of the ten hub genes. As significant differences were identified in the expression levels of EGFR, SYK, ICAM1 and CD44 in PCa compared with adjacent normal tissues, the GEPIA database was used in the present study to analyze the correlations among these genes. The results revealed that ICAM1 may be associated with IL6 and CXCL8. ICAM1 and CXCL8 were positively correlated $(\mathrm{P}<0.001 ; \mathrm{R}=0.88)$, and ICAM1 and IL6 were positively correlated $(\mathrm{P}<0.001 ; \mathrm{R}=0.52)$ (Fig. 6A and $\mathrm{B})$. EGFR and $\mathrm{CD} 44$ were

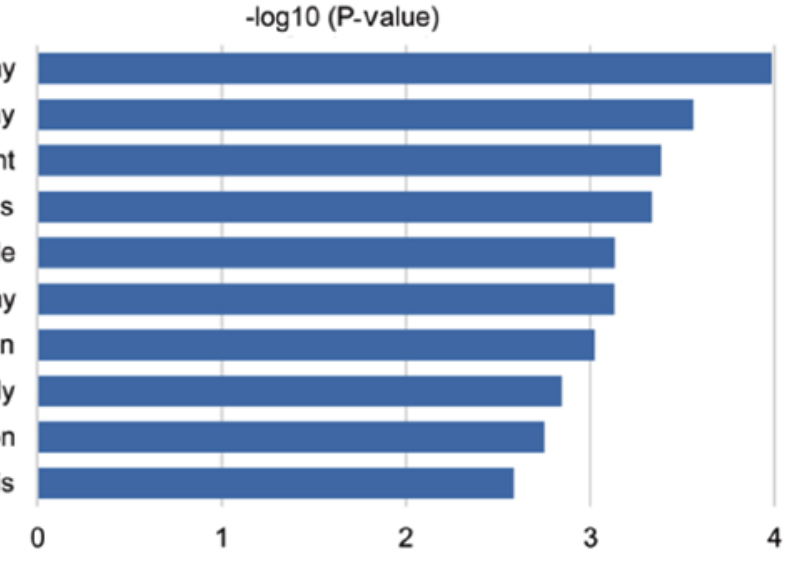

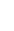




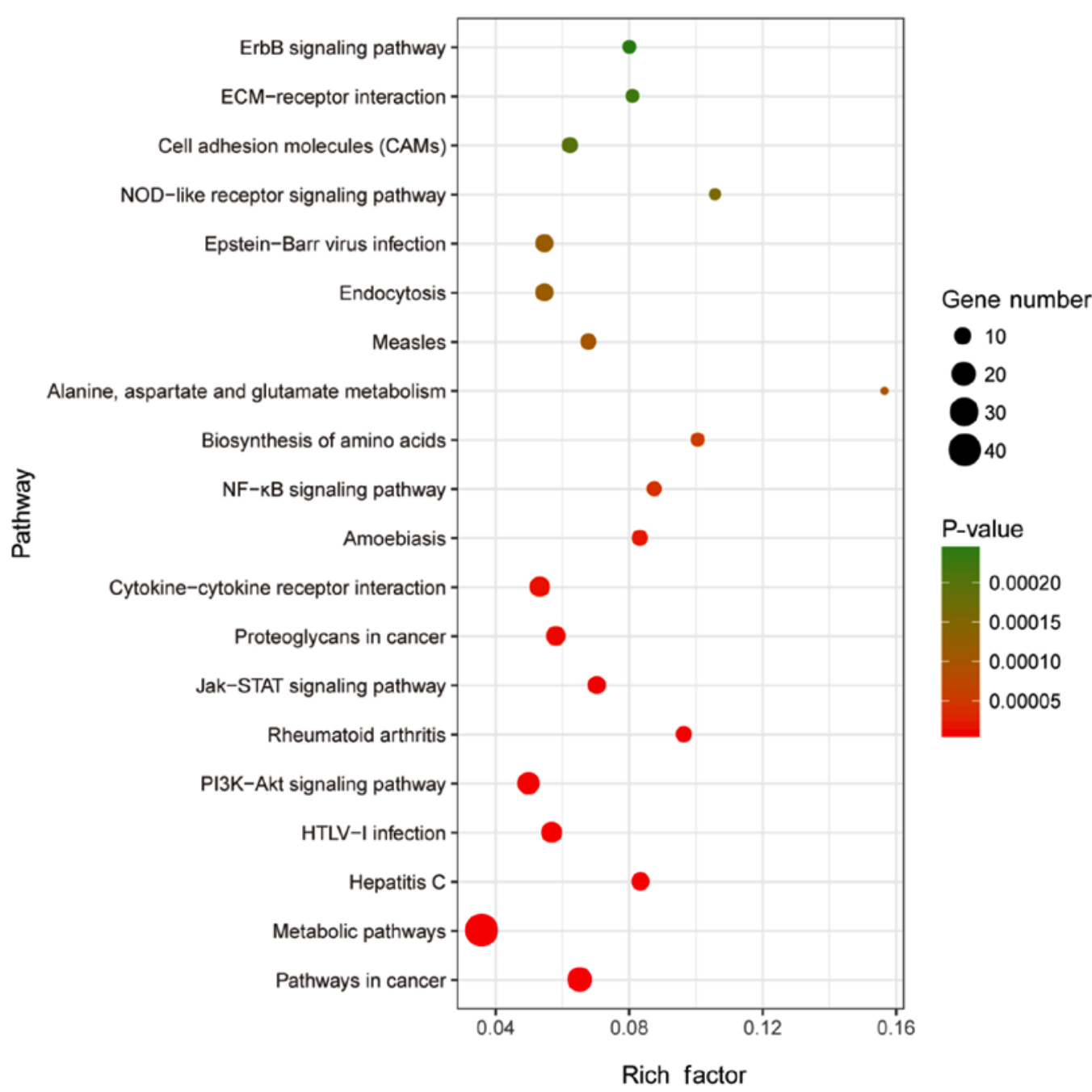

Figure 3. KEGG enrichment analysis of all DEGs with Ifold changel $>2$. All DEGs were analyzed by KEGG enrichment analysis. A fold-change $>2$ was selected as the cut-off value. KEGG, Kyoto Encyclopedia of Genes and Genomes.

and $\mathrm{CDH} 1$ in DU-145 cells were significantly lower compared with those in DU-145R cells (Fig. 7A), whereas CDK1, OAS2, OAS3, CXCL8, CDH1 and IL6 expression levels in PC-3 cells were lower compared with those in PC-3R cells (Fig. 7B).

\section{Discussion}

In the present study, 756 DEGs were identified between two docetaxel-sensitive prostate cell lines and two docetaxel-resistant prostate cell lines by analysis of the GSE33455 dataset. The DEGs included 247 upregulated genes and 509 downregulated genes. The interactions among these DEGs were investigated with KEGG and GO enrichment analyses; the DEGs were predominantly enriched in the 'interferon-gamma-mediated signaling pathway' in the BP category. In addition, other notable enriched terms included 'bicellular tight junction assembly', 'cell-cell adhesion' and the 'transforming growth factor beta receptor signaling pathway', all of which are closely associated with tumor metastasis and drug resistance. In the MF category, the DEGs were associated with 'protein binding', 'identical protein binding', 'cadherin binding involved in cell-cell adhesion', 'actin binding' and 'GTPase activity'; these data suggested that the DEGs may affect the binding of proteins, cadherin, actin and GTPase activity. In the CC category, the DEGs were mainly enriched in the 'bicellular tight junction', 'cytosol', 'extracellular exosome' and 'receptor complex'; these data indicated that the DEGs were mainly involved in substance transfer and transport in the cytoplasm of cells.

According to the KEGG analysis, the DEGs were mainly enriched in 'pathways in cancer', 'metabolic pathways', the 'PI3K-Akt signaling pathway', the 'Jak-STAT signaling pathway', 'proteoglycans in cancer' and the 'NF- $\mathrm{BB}$ signaling pathway'. Chen et al (8) have demonstrated that upregulated inositol polyphosphate-4-phosphatase type II B induces apoptosis and enhances sensitivity to docetaxel via the PI3K/Akt signaling pathway in PC3-DR and DU-145-DR cells. NF- $\mathrm{KB}$ signaling serves a crucial role in regulating invasion, metastasis, proliferation, angiogenesis and drug resistance in tumor cells. A previous study reported that the NF- $\kappa B$ pathway may be a potential target for combination therapy during the advanced stages of thyroid cancer (27). In addition, NF- $\kappa B$, pAkt, macrophage inhibitory cytokine-1 and EGFR, which are significantly overexpressed in PCa samples, induce caspase-dependent apoptosis and increase the sensitivity of cytotoxic effects caused by docetaxel in chemo-resistant SP WPE1-NB26 cells (28). This indicates the crucial roles of the 


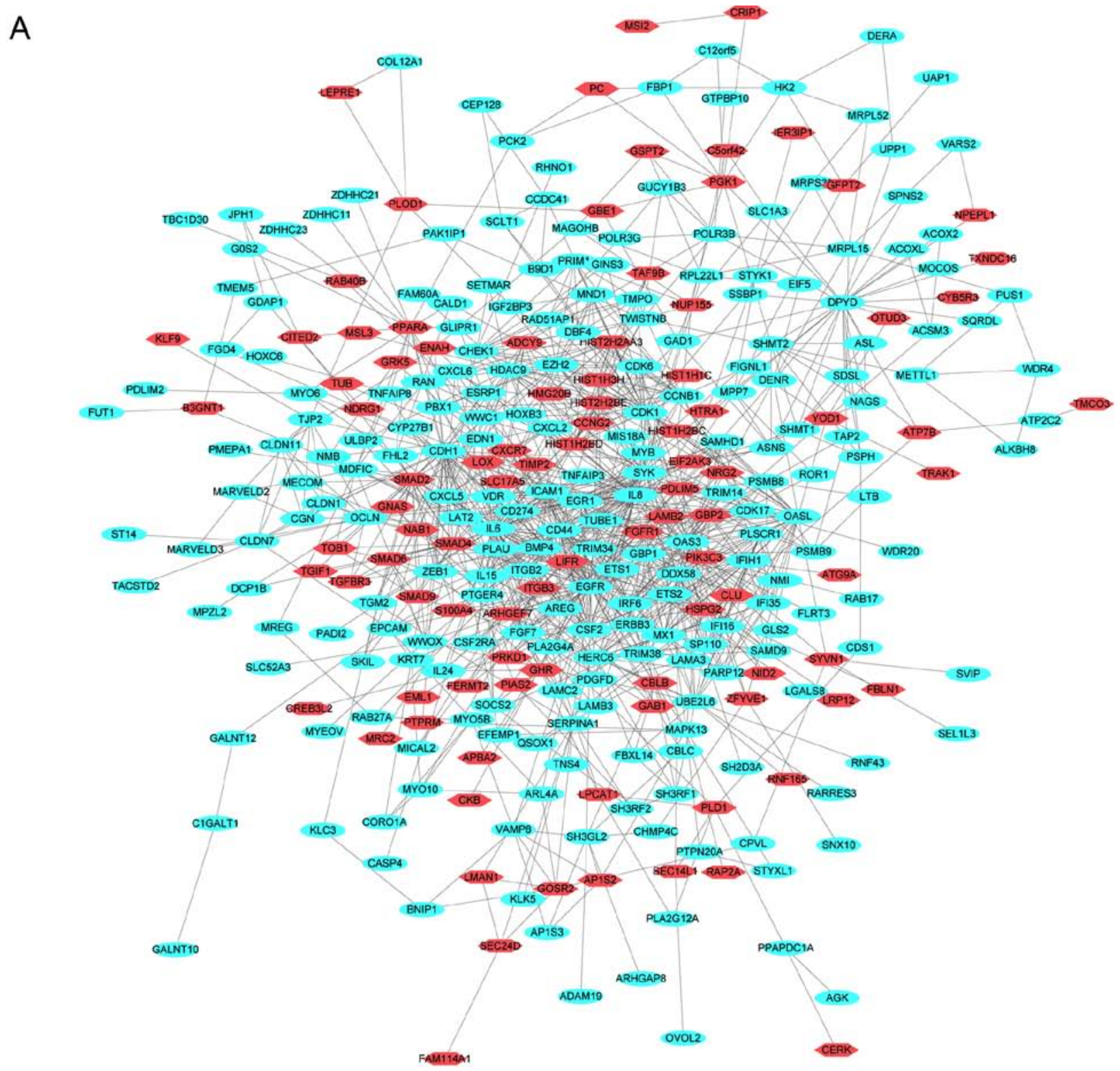

B

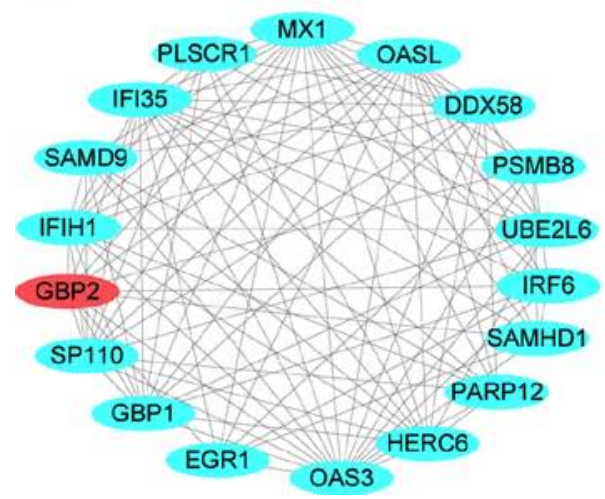

C

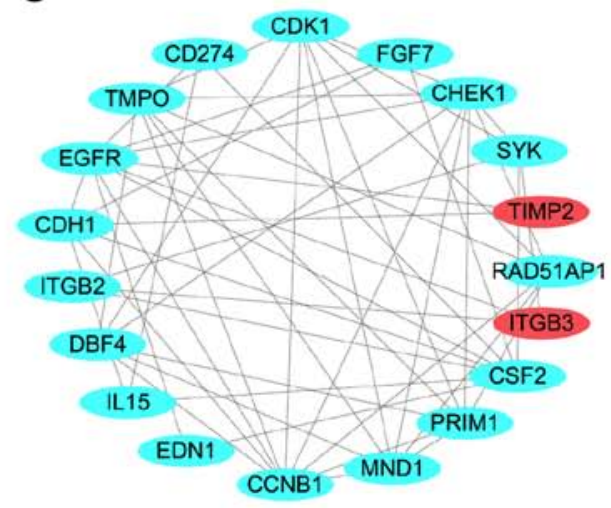

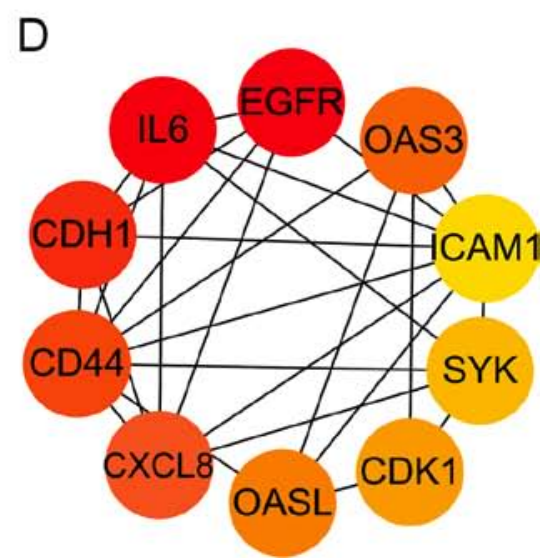

Figure 4. PPI network of the DEGs and modular analysis. (A) A PPI network of the DEGs was constructed using Cytoscape software. Red nodes represent upregulated genes and cyan nodes represent down-regulated genes. (B) Module one was selected from the PPI network with 18 nodes and 105 edges. (C) Module two was selected from the PPI network with 19 nodes and 53 edges. (D) The top ten hub genes with a degree $>28$ were selected from the PPI network. A deeper the color of the circle represents a higher degree score. PPI, protein-protein interaction; DDX58/IFIH1, DExD/H-Box helicase 58/interferon induced with helicase $\mathrm{C}$ domain 1.

$\mathrm{PI} 3 \mathrm{~K} / \mathrm{Akt}$ and $\mathrm{NF}-\kappa \mathrm{B}$ signaling pathways in $\mathrm{PCa}$ resistance to docetaxel.
In the present study, a PPI network was constructed using the DEGs with 324 nodes and 1,087 edges, and two notable 
Table I. GO and KEGG pathway enrichment analysis of module 1.

\begin{tabular}{llll}
\hline Term & \multicolumn{1}{c}{ Description } & $-\log 10($ P-value $)$ & \\
\hline R-HSA-913531 & Interferon signaling & 20.627 & $\begin{array}{l}\text { EGR1, GBP1, GBP2, IFI35, IRF6, } \\
\text { MX1, OAS3, PSMB8, OASL, } \\
\end{array}$ \\
GO:0051607 & Defense response to virus & & UBE2L6, DDX58, SAMHD1 \\
& & 11.488 & GBP1, MX1, OAS3, PLSCR1, OASL, \\
& & & DDX58, SAMHD1, IFIH1, SP110, \\
GO:0060333 & Interferon-gamma-mediated signaling pathway & 8.152 & GSMB8 \\
R-HSA-936440 & Negative regulators of DDX58/IFIH1 signaling & 5.599 & UBE2L6, DDX58, IFIH1, MX1, \\
& & & OAS3, PLSCR1, PSMB8, SAMHD1, \\
& & & GBP1, EGR1 \\
R-HSA-1169408 & ISG15 antiviral mechanism & 4.627 & MX1, UBE2L6, DDX58 \\
R-HSA-983168 & Antigen processing: Ubiquitination \& & 2.744 & PSMB8, UBE2L6, HERC6 \\
& Proteasome degradation & & \\
GO:0002429 & Immune response-activating cell surface & 2.362 & GBP1, PLSCR1, PSMB8 \\
& receptor signaling pathway & &
\end{tabular}

GO, gene ontology; KEGG, Kyoto Encyclopedia of Genes and Genomes, DDX58/IFIH1, DExD/H-Box helicase 58/interferon induced with helicase C domain 1.

Table II. GO and KEGG pathway enrichment analysis of module 2.

\begin{tabular}{|c|c|c|c|}
\hline Term & Description & -log10(P-value) & Genes \\
\hline GO:0050730 & $\begin{array}{l}\text { Regulation of peptidyl-tyrosine } \\
\text { phosphorylation }\end{array}$ & 9.269 & $\begin{array}{l}\text { CSF2, EGFR, FGF7, IL15, ITGB2, ITGB3, SYK, } \\
\text { CD274, CDH1, EDN1, TIMP2 }\end{array}$ \\
\hline GO:0042554 & Superoxide anion generation & 8.073 & $\begin{array}{l}\text { EDN1, EGFR, ITGB2, SYK, CCNB1, CDK1, } \\
\text { FGF7, ITGB3, CD274, CSF2, TIMP2, IL15 }\end{array}$ \\
\hline GO:0006260 & DNA replication & 6.949 & $\begin{array}{l}\text { CDK1, CHEK1, CSF2, EGFR, PRIM1, DBF4, } \\
\text { CCNB1, TMPO, MND1, EDN1, IL15, TIMP2, } \\
\text { FGF7, SYK, ITGB2, CDH1 }\end{array}$ \\
\hline GO:0007568 & Ageing & 6.941 & CDK1, CHEK1, EDN1, IL15, ITGB2, TIMP2 \\
\hline hsa04015 & Rap1 signaling pathway & 6.155 & $\begin{array}{l}\text { CDH1, EGFR, FGF7, ITGB2, ITGB3, IL15, SYK, } \\
\text { CDK1, CSF2, EDN1, CD274, PRIM1, CHEK1 }\end{array}$ \\
\hline GO:0098609 & Cell-cell adhesion & 5.708 & $\begin{array}{l}\text { CDH1, EGFR, IL15, ITGB2, ITGB3, SYK, CD274, } \\
\text { TIMP2 }\end{array}$ \\
\hline GO:0010035 & Response to inorganic substance & 5.550 & $\begin{array}{l}\text { CCNB1, CDK1, CDH1, CSF2, EDN1, EGFR, } \\
\text { ITGB3, FGF7, SYK, CD274, IL15, CHEK1, ITGB2 }\end{array}$ \\
\hline GO:0051052 & Regulation of DNA metabolic process & 4.842 & $\begin{array}{l}\text { CDK1, CHEK1, CSF2, EGFR, RAD51AP1, MND1, } \\
\text { EDN1, SYK }\end{array}$ \\
\hline hsa05166 & HTLV-I infection & 4.259 & $\begin{array}{l}\text { CHEK1, CSF2, IL15, ITGB2, EDN1, } \\
\text { FGF7, TIMP2 }\end{array}$ \\
\hline hsa05203 & Viral carcinogenesis & 3.215 & CDK1, CHEK1, SYK \\
\hline
\end{tabular}

GO, gene ontology; KEGG, Kyoto Encyclopedia of Genes and Genomes; HTLV-I, human T-lymphotropic virus 1.

modules termed module one and module two were obtained. Module one comprised 18 genes, including interferon induced protein 35 , phospholipid scramblase 1, guanylate binding protein 1 and ubiquitin conjugating enzyme E2 L6, which were enriched in 'defense response to virus', 'interferon-gamma-mediated signaling pathway' and 'negative regulators of DDX58/IFIH1 signaling'. These enrichments result in the interaction of multiple signal transduction pathways in effector cells and the expression of associated stimulatory genes, which have many biological functions, including 
Table III. Degrees and functions of the top 10 hub genes in the protein-protein interaction network.

\begin{tabular}{|c|c|c|c|}
\hline Gene & Full name & Degree & Function \\
\hline ICAM1 & Intercellular Adhesion Molecule 1 & 29 & $\begin{array}{l}\text { Overexpressed in various cancers and may be involved in the } \\
\text { progression of cancer }\end{array}$ \\
\hline SYK & Spleen-associated tyrosine kinase & 30 & $\begin{array}{l}\text { Immune cell signaling pathways, including proliferation, } \\
\text { differentiation and phagocytosis }\end{array}$ \\
\hline CDK1 & Cyclin-dependent kinase 1 & 34 & $\begin{array}{l}\text { Regulates cell viability, cell cycle progression, apoptosis and DNA } \\
\text { damage repair of tumor cells }\end{array}$ \\
\hline OASL & 2'-5'-oligoadenylate synthetase-like & 35 & Negative role in the anti-tumor immune response \\
\hline OAS3 & 2'-5'-oligoadenylate synthetase 3 & 36 & $\begin{array}{l}\text { Cellular innate antiviral response, apoptosis, cell growth, } \\
\text { differentiation and gene regulation }\end{array}$ \\
\hline CXCL8 & CXC motif chemokine ligand 8 & 38 & $\begin{array}{l}\text { Overexpressed in multiple cancer types; promotes the acquisition of } \\
\text { mesenchymal features, stemness, resistance to therapy }\end{array}$ \\
\hline CD44 & CD44 molecule & 38 & $\begin{array}{l}\text { Cell-surface glycoprotein involved in cell-cell interactions, cell } \\
\text { adhesion and migration }\end{array}$ \\
\hline CDH1 & Cadherin 1 & 43 & $\begin{array}{l}\text { Loss of CDH1 is associated with migration, invasion and poor } \\
\text { prognosis of multiple cancers }\end{array}$ \\
\hline IL6 & Interleukin 6 & 57 & Immune response to cancer and inflammatory diseases \\
\hline EGFR & Epidermal growth factor receptor & 59 & Promotes the proliferation of multiple cancer types \\
\hline
\end{tabular}

antivirus, antitumor and immune regulatory functions (29). Module two consisted of 19 genes, including CDK1, cyclin B1, meiotic nuclear divisions 1 , DNA primase subunit 1 , checkpoint kinase 1 , colony stimulating factor 2 and $\mathrm{CDH} 1$, which were mainly associated with 'regulation of peptidyl-tyrosine phosphorylation', 'DNA replication', 'cell-cell adhesion' and the 'Rap1 signaling pathway'. It has been reported that these enrichment results are mainly involved in the processes of tumor adhesion, invasion, metastasis and drug resistance (30). The top ten DEGs with a degree of connectivity $>28$ were considered as the hub genes, including ICAM1, SYK, CDK1, OASL, OAS3, CXCL8, CD44, CDH1, EGFR and IL6, which may serve critical roles in docetaxel-resistance in $\mathrm{PCa}$. Analysis using data from TCGA database demonstrated that the expression levels of ICAM1 and CDK1 were significantly higher in PCa tissues compared with normal tissues, whereas the expression levels of SYK, CXCL8, CD44, EGFR and IL6 were significantly lower. Tumor cells promote growth by avoiding or preventing the immune response (31). Therefore, it can be hypothesized that ICAM-1, a co-stimulatory molecule, may promote tumor survival by signaling to natural killer cells and cytotoxic T lymphocytes (32). Several studies have demonstrated that CXCL8 is associated with the migration and proliferation of various types of cancer cells, including PCa cells $(33,34)$. CXCL8 promotes the proliferation and progression of cancer cells and increases the resistance to cytotoxic drugs in androgen-independent PCa by upregulating the expression of survival factors, which promotes the growth and development of tumors (35).

Correlation analysis of the hub genes identified in the present study revealed that the expression levels of ICAM1 and CXCL8 were positively correlated $(\mathrm{P}<0.01, \mathrm{R}=0.88)$, suggesting that ICAM1 may serve an important role in docetaxel-resistance in PCa. Ghotra et al (36) demonstrated that the protein tyrosine kinase SYK may be a new therapeutic target for advanced $\mathrm{PCa}$ as it stimulates the growth and migration of PCa cells. CDK1 is essential for cell viability as it serves important roles in numerous biological events, including activating checkpoint proteins, repairing DNA damage and regulating the cell cycle (37). A previous study has indicated that abnormal activation of CDK1 promotes the proliferation and survival of PCa cells by phosphorylating and suppressing FOXO1 (38). Previous studies have demonstrated that 2'-5'-oligoadenylate synthetase (OAS) is induced by interferons when infected by viruses, as OAS-like (OASL) has a regulatory function in antiviral innate immunity via interferon signaling; the genetic variation of OAS may increase the risk of chronic lymphocytic leukemia $(39,40)$. CD44 performs versatile functions as a cell membrane receptor, including cell adhesion, invasion and metastasis in tumor cells (41). CD44 has also been identified on cancer-initiating cells and stem cells (42). CD44 performs a tumor-promoter function by mediating the invasion, proliferation and migration of PCa PC-3 cells; inhibition of CD44 decreases the glucose consumption and increase the sensitivity to docetaxel of PC-3 cells. This suggests that CD44 exhibits a regulatory effect on the progression and drug resistance of PCa cells (43). Furthermore, Jiang et al (44) reported that a mutation of the CDH1 gene is associated with metastasis and invasion in numerous types of cancer, as it changes the transcriptional activity of epithelial cells. Epigenetic loss of $\mathrm{CDH} 1$ is associated with multidrug resistance in human hepatocellular carcinoma cells (44). Additionally, EGFR has been demonstrated to be a driver of tumorigenesis by promoting the proliferation and development of a number of different cancer types (45). Hour et al (46) have demonstrated a positive correlation between EGFR expression and resistance to docetaxel, which was mediated by EGFR via the Akt/ABCB1 

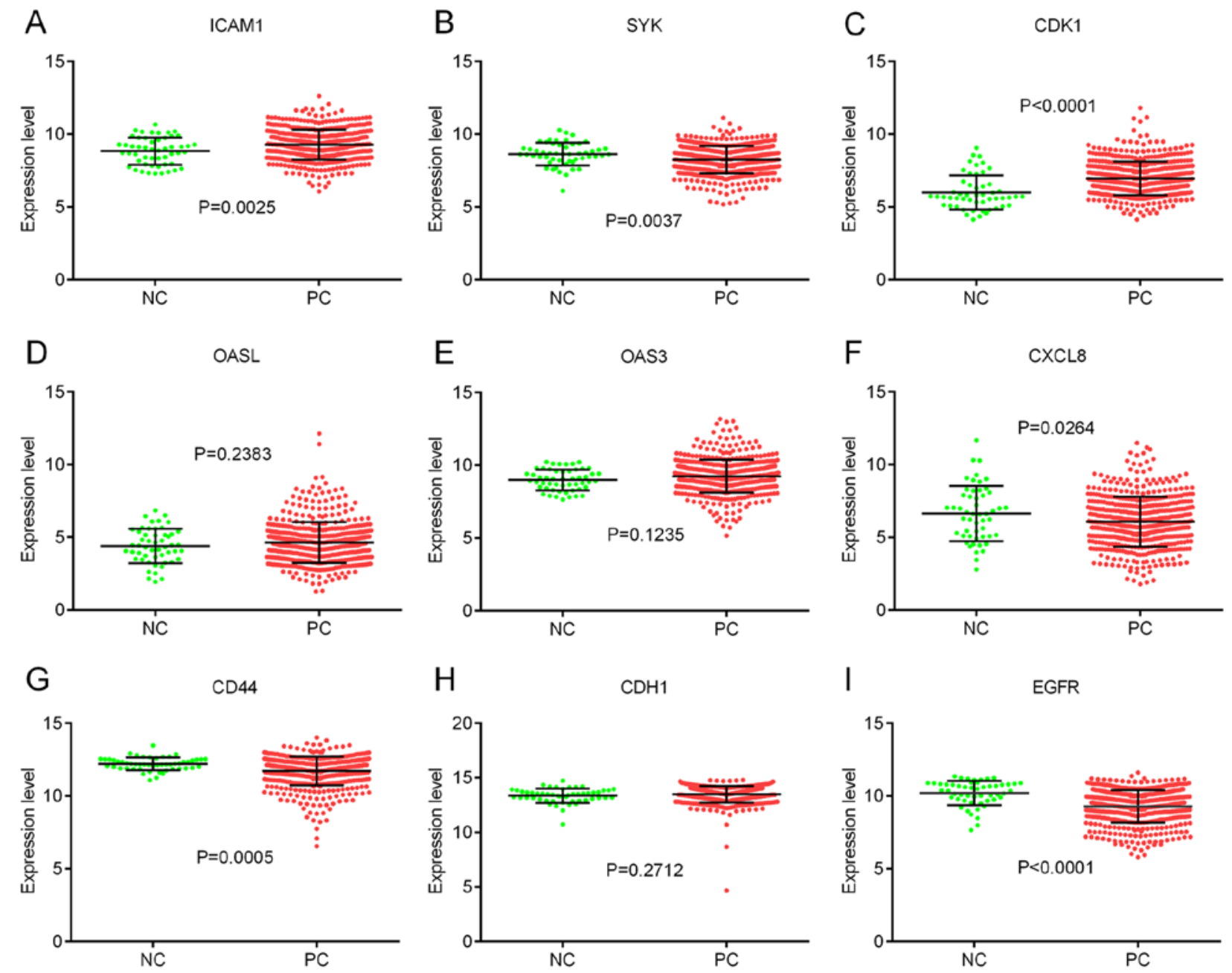

$\mathrm{J}$

IL6

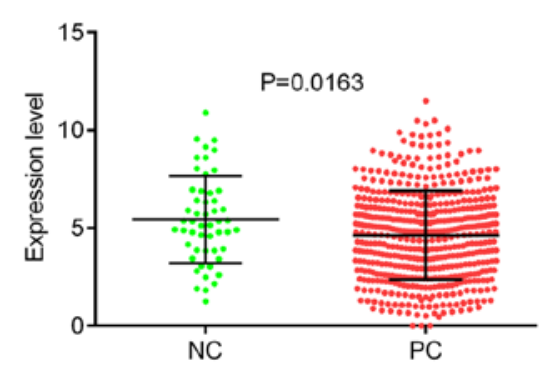

Figure 5. Expression levels of the ten hub genes in PC and NC downloaded from TCGA database. (A) ICAM1 expression in NC was lower than that in PC. $\mathrm{P}=0.0025$. (B) SYK expression in NC was higher than that in $\mathrm{PC}$. $\mathrm{P}=0.0037$. (C) CDK1 expression in NC was lower than that in PC. $\mathrm{P}<0.0001$. (D) No difference in OASL expression was identified between NC and PC. $P=0.2383$. (E) No difference in OAS3 expression was identified between NC and PC. $P=0.1235$. (F) CXCL8 expression in NC was higher than that in PC. $\mathrm{P}=0.0264$. (G) CD44 expression in NC was higher than that in PC. $\mathrm{P}=0.0005$. (H) No difference in $\mathrm{CDH} 1$ expression was identified between NC and PC. $\mathrm{P}=0.2712$. (I) EGFR expression in NC was higher than that in PC. P<0.0001. (J) IL6 expression in NC was higher than that in PC. $\mathrm{P}=0.0163$. NC, normal tissue samples; PC, prostate cancer tissue samples.

pathway in PCa cells, and an increased susceptibility to docetaxel-based treatment while dealt with EGFR inhibition. These findings indicate that EGFR serves a crucial role in docetaxel-resistant PCa. IL6, an inflammatory factor associated with inflammation-driven cancer, performs an important role in the resistance to EGFR drugs. A recent study suggested that co-targeting EGFR and IL6 may exhibit potential as a new cancer treatment, as crosstalk between the EGFR and IL6 signaling pathways contributes to drug resistance (47). The present study demonstrated positive correlations between
EGFR and CD44 and between EGFR and SYK expression levels.

In summary, a total of 756 DEGs and ten hub genes were identified in the current study. Bioinformatics analysis demonstrated that ICAM1, CXCL8, CD44, SYK, EGFR and IL6 were upregulated in the docetaxel-resistant PCa cell lines, and RT-qPCR analysis confirmed that a number of the hub genes, including CHK1, OAS3, CXCL8 and CDH1, were highly expressed in the docetaxel-resistant cell lines; these data suggested that these genes may be the core genes involved in 

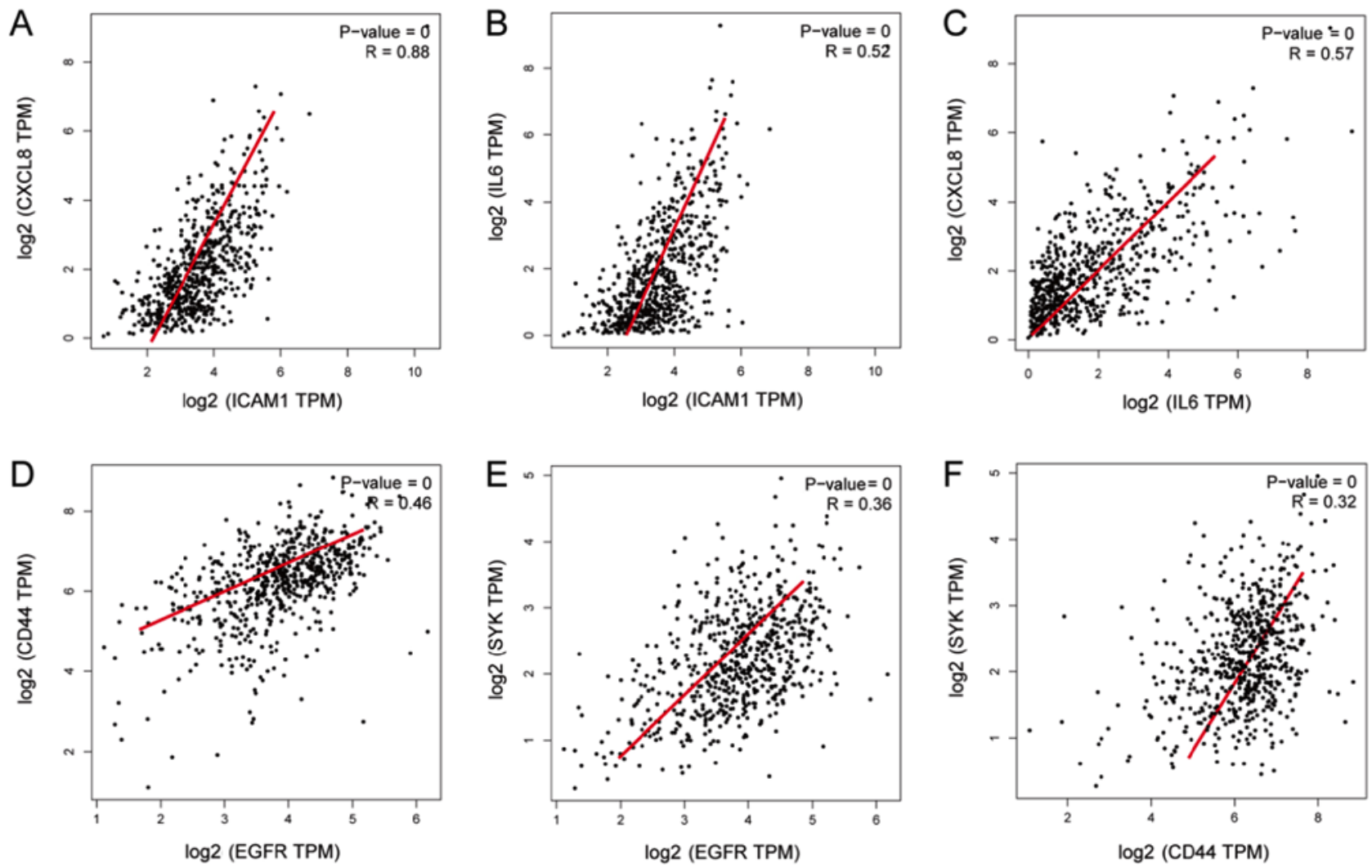

Figure 6. Correlation analysis of the hub genes was conducted using the GEPIA tool. (A) ICAM1 and CXCL8 were positively correlated ( $\mathrm{P}<0.01$; R=0.88). (B) ICAM1 and IL6 were positively correlated ( $\mathrm{P}=0.00 ; \mathrm{R}=0.52$ ). (C) CXCL8 and IL6 were positively correlated ( $\mathrm{P}=0.00 ; \mathrm{R}=0.57)$. (D) $\mathrm{EGFR}$ and $\mathrm{CD} 44$ were positively correlated $(\mathrm{P}=0.00 ; \mathrm{R}=0.46)$. (E) EGFR and $\mathrm{SYK}$ were positively correlated $(\mathrm{P}=0.00 ; \mathrm{R}=0.36)$. ( $\mathrm{F}) \mathrm{CD} 44$ and $\mathrm{SYK}$ were positively correlated $(\mathrm{P}=0.00 ; \mathrm{R}=0.32)$. ICAM1, intracellular adhesion molecule 1; CXCL8, CXC motif chemokine ligand 8; IL6, interleukin 6; EGFR, epidermal growth factor receptor; CD44, adhesive molecule CD44; SYK, spleen tyrosine kinase; TPM; transcripts per million reads.

A

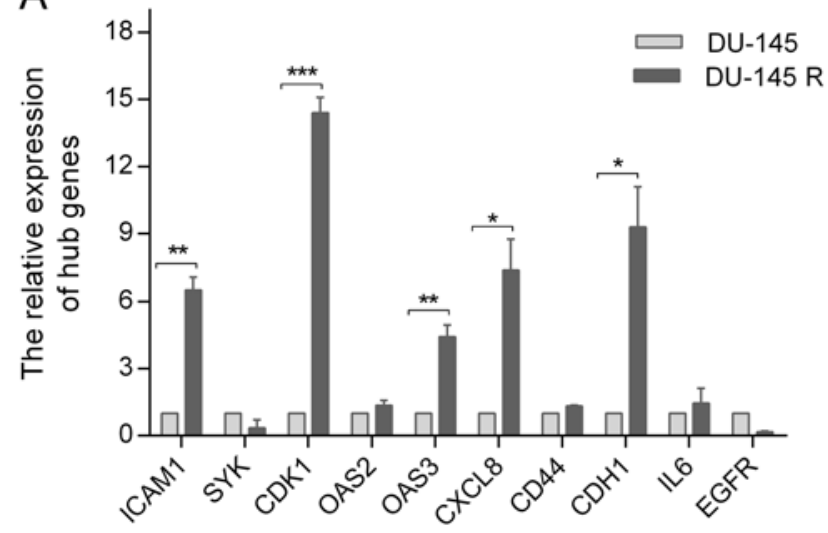

B

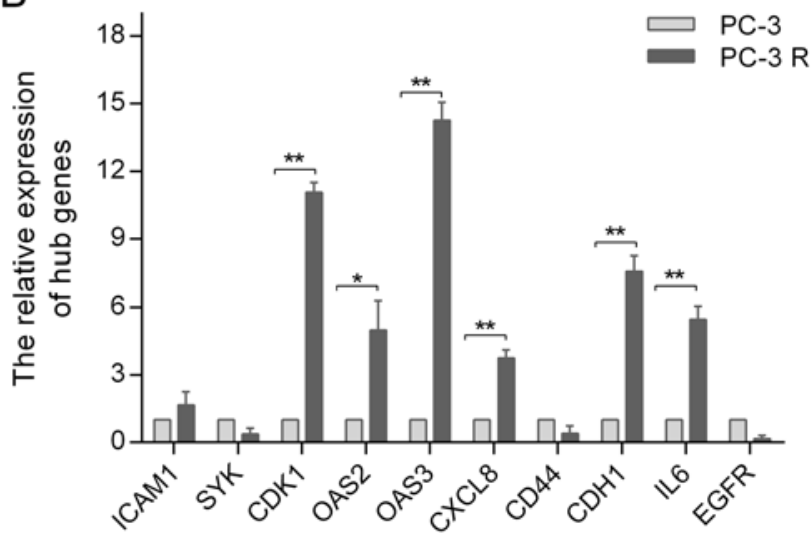

Figure 7. Hub genes are differently expressed in docetaxel-sensitive and docetaxel-resistant PCa cell lines. (A) The mRNA levels of the hub genes in DU-145 cells and DU-145R cells were determined by RT-qPCR. (B) The mRNA levels of the hub genes in PC-3 cells and PC-3R cells were determined by RT-qPCR. The relative mRNA expression was normalized to $\beta$-actin expression. DU-145 or $\mathrm{PC}-3$ cells were used as the control groups. $\mathrm{N}=3$. ${ }^{*} \mathrm{P}<0.05$, ${ }^{* *} \mathrm{P}<0.01$ and ${ }^{* * * *} \mathrm{P}<0.001$ vs. the respective control. DU-145R, docetaxel-resistant DU-145 cells; PC-3R cells, docetaxel-resistant PC-3 cells; RT-qPCR, reverse transcription-quantitative PCR.

the mechanism of docetaxel resistance in $\mathrm{PCa}$. The data from the present study suggested that these genes may be closely associated the carcinogenesis, progression, prognosis and drug resistance of $\mathrm{PCa}$.

In conclusion, the present preliminary study revealed several hub genes associated with docetaxel resistance by comprehensive bioinformatics analysis, which may assist with improving the understanding of the underlying molecular mechanisms of docetaxel resistance. Combined targeted therapy of multiple genes and pathways is of great significance to investigate the mechanism of docetaxel-resistance. However, a limitation of the present study is that only a single platform based on docetaxel sensitivity and docetaxel resistance in $\mathrm{PCa}$ was analyzed. Furthermore, the current study was focused on 
bioinformatics and the results only verified by RT-qPCR in cell lines; therefore, the conclusion remains to be confirmed by in vivo experiments. Studies involving experiments and larger sample sizes are required to further confirm the present results in the future.

\section{Acknowledgements}

Not applicable.

\section{Funding}

The present study was funded by the Project of Youth Science Foundation of Jiangxi Science and Technology Office (grant no. 20171BAB215015).

\section{Availability of data and materials}

The datasets used and/or analyzed during the current study are available from the corresponding author on reasonable request.

\section{Authors' contributions}

LD and XG contributed to the study design, data acquisition and analysis and drafted the manuscript. HC participated in the study design, data acquisition and revision of the manuscript. TZ, FX, ZD and CL assisted in the performance of the statistical analysis. All authors read and approved the final manuscript.

\section{Ethics approval and consent to participate}

Not applicable.

\section{Patient consent for publication}

Not applicable.

\section{Competing interests}

The authors declare that they have no competing interests.

\section{References}

1. Siegel RL, Miller KD and Jemal A: Cancer statistics, 2019. CA Cancer J Clin 69: 7-34, 2019.

2. Wong MC, Goggins WB, Wang HH, Fung FD, Leung C, Wong SY, Ng CF and Sung JJ: Global incidence and mortality for prostate cancer: Analysis of temporal patterns and trends in 36 countries. Eur Urol 70: 862-874, 2016.

3. Tsao CK, Galsky MD and Oh WK: Docetaxel for metastatic Hormone-sensitive prostate cancer: Urgent need to minimize the risk of neutropenic fever. Eur Urol 70: 707-708, 2016.

4. Fizazi K, Ulys A, Sengeløv L, Moe M, Ladoire S, ThieryVuillemin A, Flechon A, Guida A, Bellmunt J, Climent MA, et al A randomized, double-blind, placebo-controlled phase II study of maintenance therapy with tasquinimod in patients with metastatic castration-resistant prostate cancer responsive to or stabilized during first-line docetaxel chemotherapy. Ann Oncol 28: 2741-2746, 2017.

5. Thadani-Mulero M, Portella L, Sun S, Sung M, Matov A, Vessella RL, Corey E, Nanus DM, Plymate SR and Giannakakou P: Androgen receptor splice variants determine taxane sensitivity in prostate cancer. Cancer Res 74: 2270-2282, 2014.
6. Ploussard G, Terry S, Maillé P, Allory Y, Sirab N, Kheuang L, Soyeux P, Nicolaiew N, Coppolani E, Paule B, et al: Class III beta-tubulin expression predicts prostate tumor aggressiveness and patient response to docetaxel-based chemotherapy. Cancer Res 70: 9253-9264, 2010.

7. Zhu Y, Liu C, Nadiminty N, Lou W, Tummala R, Evans CP and Gao AC: Inhibition of ABCB1 expression overcomes acquired docetaxel resistance in prostate cancer. Mol Cancer Ther 12: 1829-1836, 2013

8. Chen $\mathrm{H}, \mathrm{Li} \mathrm{H}$ and Chen Q: INPP4B reverses docetaxel resistance and epithelial-to-mesenchymal transition via the PI3K/Akt signaling pathway in prostate cancer. Biochem Biophys Res Commun 477: 467-4672, 2016.

9. De Bessa Garcia SA, Pavanelli AC, Cruz E Melo N and Nagai MA: Prostate apoptosis response 4 (PAR4) expression modulates WNT signaling pathways in MCF7 breast cancer cells: A possible mechanism underlying PAR4-mediated docetaxel chemosensitivity. Int J Mol Med 39: 809-818, 2017.

10. Codony-Servat J, Marín-Aguilera M, Visa L, García-Albéniz X, Pineda E, Fernández PL, Filella X, Gascón P and Mellado B: Nuclear factor-kappa B and interleukin-6 related docetaxel resistance in castration-resistant prostate cancer. Prostate 73: 512-521, 2013.

11. Marín-Aguilera M, Codony-Servat J, Reig Ò, Lozano JJ, Fernández PL, Pereira MV, Jiménez N, Donovan M, Puig P and Mengual L: Epithelial-to-mesenchymal transition mediates docetaxel resistance and high risk of relapse in prostate cancer. Mol Cancer Ther 13: 1270-1284, 2014.

12. Sotiriou $\mathrm{C}$ and Piccart MJ: Taking gene-expression profiling to the clinic: When will molecular signatures become relevant to patient care? Nat Rev Cancer 7: 545-553, 2007.

13. Marín-Aguilera M, Codony-Servat J, Kalko SG, Fernández PL, Bermudo R, Buxo E, Ribal MJ, Gascón P and Mellado B: Identification of docetaxel resistance genes in castration-resistant prostate cancer. Mol Cancer Ther 11: 329-339, 2012.

14. Irizarry RA, Hobbs B, Collin F, Beazer-Barclay YD, Antonellis KJ, Scherf U and Speed TP: Exploration, normalization, and summaries of high density oligonucleotide array probe level data. Biostatistics 4: 249-264, 2003.

15. Ritchie ME, Phipson B, Wu D, Hu Y, Law CW, Shi W and Smyth GK: Limma powers differential expression analyses for RNA-sequencing and microarray studies. Nucleic Acids Res 43: e47, 2015.

16. Wang L, Cao C, Ma Q, Zeng Q, Wang H, Cheng Z, Zhu G, Qi J, $\mathrm{Ma} \mathrm{H}$, Nian $\mathrm{H}$ and Wang Y: RNA-seq analyses of multiple meristems of soybean: Novel and alternative transcripts, evolutionary and functional implications. BMC Plant Biol 14: 169, 2014.

17. Tian Z, Wang C, Guo M, Liu X and Teng Z: An improved method for functional similarity analysis of genes based on Gene Ontology. BMC Syst Biol 10 (Suppl 4): S119, 2016.

18. Kanehisa M, Goto S, Sato Y, Furumichi M and Tanabe M: KEGG for integration and interpretation of large-scale molecular data sets. Nucleic Acids Res 40 (Database Issue): D109-D114, 2012.

19. Huang da W, Sherman BT and Lempicki RA: Systematic and integrative analysis of large gene lists using DAVID bioinformatics resources. Nat Protoc 4: 44-57, 2009.

20. Franceschini A, Szklarczyk D, Frankild S, Kuhn M, Simonovic M, Roth A, Lin J, Minguez P, Bork P, von Mering C and Jensen LJ: STRING v9.1: Protein-protein interaction networks, with increased coverage and integration. Nucleic Acids Res 41 (Database Issue): D808-D815, 2013.

21. Smoot ME, Ono K, Ruscheinski J, Wang PL and Ideker T: Cytoscape 2.8: New features for data integration and network visualization. Bioinformatics 27: 431-432, 2011.

22. Almeida D, Azevedo V, Silva A and Baumbach J: PetriScape-A plugin for discrete Petri net simulations in Cytoscape. J Integr Bioinform 13: 284, 2016.

23. Chin $\mathrm{CH}$, Chen SH, Wu HH, Ho CW, Ko MT and Lin CY: cytoHubba: Identifying hub objects and sub-networks from complex interactome. BMC Syst Biol 8 (Suppl 4): S11, 2014.

24. Tang Z, Li C, Kang B, Gao G, Li C and Zhang Z: GEPIA: A web server for cancer and normal gene expression profiling and interactive analyses. Nucleic Acids Res 45: W98-W102, 2017.

25. Lin JZ, Wang ZJ, De W, Zheng M, Xu WZ, Wu HF, Armstrong A and Zhu JG: Targeting AXL overcomes resistance to docetaxel therapy in advanced prostate cancer. Oncotarget 8: 41064-41077, 2017.

26. Livak KJ and Schmittgen TD: Analysis of relative gene expression data using real-time quantitative PCR and the 2(-Delta Delta C(T)) method. Methods 25: 402-408, 2001. 
27. Pozdeyev N, Berlinberg A, Zhou Q, Wuensch K, Shibata H, Wood WM and Haugen BR: Targeting the NF- $\kappa$ B pathway as a combination therapy for advanced thyroid cancer. PLoS One 10: e0134901, 2015

28. Mimeault M, Johansson SL and Batra SK: Pathobiological implications of the expression of EGFR, pAkt, NF- $\mathrm{BB}$ and MIC-1 in prostate cancer stem cells and their progenies. PLoS One 7: e31919, 2012.

29. Haralambieva IH, Ovsyannikova IG, Umlauf BJ, Vierkant RA, Shane Pankratz V, Jacobson RM and Poland GA: Genetic polymorphisms in host antiviral genes: Associations with humoral and cellular immunity to measles vaccine. Vaccine 29: 8988-8997, 2011.

30. Xue Y, Rushton MD and Maringele L: A novel checkpoint and RPA inhibitory pathway regulated by Rif 1 . PLoS Genet 7: e1002417, 2011.

31. Croci DO and Salatino M: Tumor immune escape mechanisms that operate during metastasis. Curr Pharm Biotechnol 12: 1923-1936, 2011

32. Slavin-Chiorini DC, Catalfamo M, Kudo-Saito C, Hodge JW, Schlom J and Sabzevari H: Amplification of the lytic potential of effector/memory CD8+ cells by vector-based enhancement of ICAM-1 (CD54) in target cells: Implications for intratumoral vaccine therapy. Cancer Gene Ther 11: 665-680, 2004.

33. Brat DJ, Bellail AC and Van Meir EG: The role of interleukin- 8 and its receptors in gliomagenesis and tumoral angiogenesis. Neuro Oncol 7: 122-133, 2005.

34. Roumeguère T, Legrand F, Rassy EE, Kaitouni MI, Albisinni S, Rousseau A, Vanhaeverbeek M, Rorive S, Decaestecker C, Debeir O, et al: A prospective clinical study of the implications of IL-8 in the diagnosis, aggressiveness and prognosis of prostate cancer. Future Scie OA 4: FSO266, 2017.

35. Araki S, Omori Y, Lyn D, Singh RK, Meinbach DM, Sandman Y, Lokeshwar VB and Lokeshwar BL: Interleukin-8 is a molecular determinant of androgen independence and progression in prostate cancer. Cancer Res 67: 6854-6862, 2007.

36. Ghotra VP, He S, van der Horst G, Nijhoff S, de Bont $H$, Lekkerkerker A, Janssen R, Jenster G, van Leenders GJ, Hoogland AM, et al: SYK is a candidate kinase target for the treatment of advanced prostate cancer. Cancer Res 75: 230-240, 2015.

37. Prevo R, Pirovano G, Puliyadi R, Herbert KJ, RodriguezBerriguete G, O'Docherty A, Greaves W, McKenna WG and Higgins GS: CDK1 inhibition sensitizes normal cells to DNA damage in a cell cycle dependent manner. Cell Cycle 17: $1513-1523,2018$.
38. Liu P, Kao TP and Huang H: CDK1 promotes cell proliferation and survival via phosphorylation and inhibition of FOXO1 transcription factor. Oncogene 27: 4733-4744, 2008.

39. Dunn GP, Old LJ and Schreiber RD: The immunobiology of cancer immunosurveillance and immunoediting. Immunity 21 : 137-148, 2004.

40. Sava GP, Speedy HE, Di Bernardo MC, Dyer MJ, Holroyd A, Sunter NJ, Marr H, Mansouri L, Deaglio S, Karabon L, et al: Common variation at 12q24.13 (OAS3) influences chronic lymphocytic leukemia risk. Leukemia 29: 748-751 2015.

41. Suarez JS, Gurler Main H, Muralidhar GG, Elfituri O, Xu HL, Kajdacsy-Balla AA and Barbolina MV: CD44 regulates formation of spheroids and controls organ-specific metastatic colonization in epithelial ovarian carcinoma. Mol Cancer Res: May 30, 2019 (Epub ahead of print). doi: 10.1158/1541-7786. MCR-18-1205.

42. Miletti-González KE, Murphy K, Kumaran MN, Ravindranath AK, Wernyj RP, Kaur S, Miles GD, Lim E, Chan R, Chekmareva $\mathrm{M}$, et al: Identification of function for CD44 intracytoplasmic domain (CD44-ICD): Modulation of matrix metalloproteinase 9 (MMP-9) transcription via novel promoter response element. J Biol Chem 287: 18995-19007, 2012.

43. Li W, Qian L, Lin J, Huang G, Hao N, Wei X, Wang W and Liang J: CD44 regulates prostate cancer proliferation, invasion and migration via PDK1 and PFKFB4. Oncotarget 8: 65143-65151, 2017.

44. Jiang L, Chan JY and Fung KP: Epigenetic loss of CDH1 correlates with multidrug resistance in human hepatocellular carcinoma cells. Biochem Biophys Res Commun 422: 739-744, 2012.

45. Sigismund S, Avanzato D and Lanzetti L: Emerging functions of the EGFR in cancer. Mol Oncol 12: 3-20, 2018.

46. Hour TC, Chung SD, Kang WY, Lin YC, Chuang SJ, Huang AM, $\mathrm{Wu}$ WJ, Huang SP, Huang $\mathrm{CY}$ and Pu YS: EGFR mediates docetaxel resistance in human castration-resistant prostate cancer through the Akt-dependent expression of ABCB1 (MDR1). Arch Toxicol 89: 591-605, 2015.

47. Ray K, Ujvari B, Ramana V and Donald J: Cross-talk between EGFR and IL-6 drives oncogenic signaling and offers therapeutic opportunities in cancer. Cytokine Growth Factor Rev 41 $18-27,2018$.

This work is licensed under a Creative Commons Attribution-NonCommercial-NoDerivatives 4.0 International (CC BY-NC-ND 4.0) License. 